\title{
Hazardous Slums: A Case Study on Visakhapatnam city
}

\author{
Dr. Ch. Subha kumar ${ }^{1}$, Ch. Guru Prasad ${ }^{2}$ \\ ${ }^{1}$ (Department of Economics, Andhra university, India) \\ ${ }^{2}$ (Department of Geology, Acharya Nagarjuna university, India)
}

\begin{abstract}
Almost 32 percent of the world Urban population lived in slums, the majority of them in the developing world. The proportion of the urban population living in slums is about seven times as high in less developed countries percent and in more developed countries (6 percent). Welfare governments pushes the social overhead capitals allocate foundlings for development for slum environment improvement programmes but some of the slums are belongings to mostly hazardous areas like hilly areas, around with dirty urban slums, highly congested areas, near railway tracks and bank of main drainages these kind of slums are impossible to improve the quality of life so these are called hazardous slums. In my research study was conducted to the hazardous areas among families residing in urban slums of Visakhapatnam city. A comprehensive questionnaire-cum-interview schedule was designed to collect information 500 were collect from hazardous slum areas by simple random techniques the results revealed that among the selected families majority of the respondents.
\end{abstract}

Key Words - Developing world, Environment, Hazardous Slum, social overhead capital,welfare.

\section{Introduction}

As cities grow, so do their slum population. According to the Global Report on Human Settlements (United Nations Human Settlements Program, 2003) 924 million people in 2001 or almost 32 percent of the world's urban population lived in slums, the majority of them in the developing world. The proportion of the urban population living in slums is about seven times as high in less developed countries (43 percent) and in more developed countries (6 percent). Although the concentration of slum dwellers is highest in African cities, in numbers alone Asia accounts for about 60 percent of urban slum residents in the world. The United Nations report estimates that if no serious action is taken, the number of slum dwellers worldwide will increase to about two billion over the next 30 years. Globally, the slum population is set to grow at the rate of 27 million per year during the period 2000-2020. In response to these projections, the Millennium Development Goals established a target to significantly improve the lives of at least 100 million slum dwellers by the year 2020 .

Mostly slum dwellers are living below the poverty line, poverty is the worst form of deprivation. One who is poor has little or no access to income, employment, education, housing, health and other basic necessities of the life. In fact it is poverty which forces one to suffer agonies and hardship including social discrimination. Slum areas have substandard houses, high density and congestion overcrowding, in sanitary conditions and absence of basic amenities like drinking water, electricity and fair price shops, etc., the slums environment is responsible for the mental outlook of the dwellers, especially its effects on growing children is most remarkable. Children daily witness scenes of violence, drunkenness and crime. The personal hygiene is poor and is reflected in their clothing and living condition. Due to unhealthy environmental conditions prevailing in the slums, diseases like TB, Cholera, Malaria and Jaundice are common Visakhapatnam slums.

\section{Specific Objectives of Study Area}

We select the pinpointed objectives for this research paper mainly focusing on the environmental pollution effect on the living conditions of the slum.

2.1. To study the socio-economic conditions of the sample households in the study area.

2.2 . To examine the factors influencing the sample households decision to dwell in the Hazardousslum-1 and Hazardous slum slum-2.

2.3. To portray the environmental conditions of the sample households.

2.4. To suggest suitable measures and policy suggestions for development of slum dwellers for better standard of living in the study area.

\section{Data Source and Methodology}

3.1 Data Source: To study the above mentioned objectives primary as well as secondary data have been used. for the primary data we collected total 500 Household sample collected from two selective urban hazardous slums each slum has 250 samples are collected with simple random sampling techniques. Secondary Data: Obtained from the Census Reports of Government of India, District Statistical Handbook of Statistics, Greater 
Visakha Municipal Corporation (GVMC) Reports, VUDA Urban Development (VUDA) Reports and various Government reports published by Bureau of Economics and Statistics, Government of Andhra Pradesh.

3.2 Methodology: For the collection of primary data, a multi-stage simple random sampling technique has been employed. For the purpose of study two urban slums i.e. one is Hazardous slum-1 and the rest is Hazardous slum-2 with contrasting characteristics have been selected purposively. The Hazardous slum-1(Priyadarsini colony) which is mostly affected with overcrowding is located near around slums and is selected to examine the impact of urbanization on environment of Visakhapatnam city. On the other hand, the most hazardous slum in the entire city i.e. Hazardous slum-2 (Gavara Kanchara palem) is selected which is located near the railway station.

3.3. Profile of the study area: for the convenience Table shown below

\begin{tabular}{|l|l|l|}
\hline Item No: & Hazardous slum -1 & Hazardous Slum -2 \\
\hline Name of the slum & PRIYADARSHINICOLONY & GAVARA KANCHARA PALEM \\
\hline Zone with in the city & I & IV \\
\hline Ward no: & $\mathbf{5}$ & $\mathbf{4 3}$ \\
\hline Total Population & 1854 & $\mathbf{1 5 1 3}$ \\
\hline Total households & $\mathbf{2 7 3}$ & $\mathbf{4 8 5}$ \\
\hline Category of slum & Non-notified & Notified \\
\hline Boundaries of slums & $\begin{array}{l}\text { N:Slum S:Slum E:Slum } \\
\text { W:Slum }\end{array}$ & $\begin{array}{l}\text { East: Railway Track West: Railway } \\
\text { Track North: Gedda South: Gedda } \\
\text { (ram muthry panhuntulu peta) }\end{array}$ \\
\hline
\end{tabular}

Table 1 Source: (GVMC - slums primary data in UCD Section)

\section{Environment and Health}

According to the Stockholm declaration on human environment in June 1972, "The governments and people should exert common efforts for the preservation and improvement of the human environment for the benefit of all the people and for their prosperity. Four factors are identified as the potential source of population. They include.

1. The prevailing natural conditions

2. Human population

3. The level of production and consumption

4. The level and use of technology

In the Indian cities these problems are essentially in the form of inadequate development and continuing poverty, unsafe drinking water, malnutrition, poor sanitation, inadequate housing and diseases etc. Some cities cannot but look upon planned instruments to improve the quality of life. Such planning, however, should entail a reappraisal of the objectives of development to provide more explicitly for the social and human needs of health, shelter, clean air, water and the beauty of natural surroundings. Our emphasis should be on the qualitative improvement of life as a whole rather than on the quantitative growth of various sectors of the economy.

As our late prime minister Smt. Indira Gandhi has put it "our attention cannot be diverted from the main question before us which is to bring basic amenities within the reach of our people and to give them better living conditions without alleviating them from nature and their environment, without despoiling nature of its beauty and of the freshness and purity so essential to our lives".

The state of health of people does not depend only on the number of doctors and hospitals but also on clean environment. If environment is conductive to the spreading of disease, the state of health will naturally be poor. The system has to be preventive as also curative, Prof. J.Longan in a paper published in the American Journal of Tropical Medicine in 1960 was able to show environmentally transmitted diseases were responsible for the sufferings of 500 million people every year, particularly infants and children.

\section{Review of Literature}

A slum areas means any areas where such dwellings predominate which by reasons of dilapidation, overcrowding, faulty arrangement of design of building, narrowness of faulty arrangement of street, lack of ventilation, light or sanitation facilities, inadequacy of open spaces and community facilities, or any combination of these factors, are detrimental to safety, health or morale. Sewage, industrial wastes, and agricultural chemicals such as fertilizers and pesticides are the main causes of water pollution. In developing nations, more than 95 percent of urban sewage is discharged untreated into rivers and bays, creating a major human health hazard. Water runoff, a nonpoint source of pollution, carries fertilizing chemicals such as phosphates and nitrates from agricultural fields and yards into lakes, streams, and rivers. These combine with 
the phosphates and nitrates from sewage to speed the growth of algae, a type of plantlike organism. The urban poor are forced to settle on hazardous areas such as toxic dumps, near refineries, near railroads and highways. The slum habitats have no infrastructure to speak of. There is no sanitation facility and no provision of drin king water. In Mumbai the sanitation ratio is one toilet seat per 500 inhabitants. The contamination of water by human and animal waste is responsible for the scourge of chronic diarrhea, which kills infants. In the slums of Delhi there are 1,500 shanty colonies housing over three million people with the average population density of $3,00,000$ people per square kilometer. Environmental pollution is one of the serious problems faced by the people in the country. Rapid population growth, industrialization and urbanization in country are adversely affecting the environment. Through the relationship is complex. Population size and growth tend to expend accelerate these human implies on the environment. All these in turn lead to increase in the population levels however the environmental pollution not only leads to deteriorating environmental conditions but also have adverse effects on the health. Predominant mode of living, and the growth in cities is related to the expansion of areas that have concentration disadvantage. The foreseeable trend is for rising inequities across a wide range of social and health dimensions. Although qualitatively different, this trend exists in both the developed and developing worlds. Improving the health of people in slums will require new analytic frameworks. The socialdeterminants approach emphasizes the role of factors that operate at multiple levels, including global, national, municipal, and neighborhood levels, in shaping health. This approach suggests that improving living conditions in such areas as housing, employment, education, equality, quality of living environment, social support, and health services is central to improving the health of urban populations. While social determinant and multilevel perspectives are not uniquely urban, they are transformed when viewed through the characteristics of cities such as size, density, diversity, and complexity. Ameliorating the immediate living conditions in the cities in which people live offers the greatest promise for reducing morbidity, mortality, and disparities in health and for improving quality of life and well being.Rapid urbanization the majority of urban residents in sub-Saharan Africa live in slums often characterized by a lack of basic services such as water and sewerage. Consequently, the urban poor often use inexpensive pit latrines. Sanitary practices in these overcrowded slums are also poor, leading to contamination of the wells. Sanitary practices of residents of a Kenyan urban slum and fecal contamination of their domestic water sources. (This cross-sectional study involved 192 respondents from Langas slum, Kenya. Forty water samples were collected from the water sources used by the respondents for laboratory analysis of coliforms. Of these 40 samples, 31 were from shallow wells, four from deep wells, and five from taps. Multiple-tube fermentation technique was used to enumerate coliform bacteria in water). The study found that most people (91percent) in the Langas slum used wells as the main source of domestic water, whereas the rest used tap water. Whereas most people used pit latrines for excreta disposal, a substantial percentage (30percent) of children excreted in the open field. The estimated distance between the pit latrines and the wells was generally short with about 40percent of the pit latrines being less than $15 \mathrm{~m}$ from the wells. The main domestic water sources were found to be highly contaminated with fecal matter. This study observed that owing to the fecal contamination, there is a high possibility of the presence of disease pathogens in the water. Thus, the water from the wells in Lang's may not be suitable for human consumption. To address this problem, treatment of the water at community or household level and intensive behavioral change in sanitary practices are recommended. Relationship between urbanization and environmental risk transition. The poor environmental health conditions and stress in cities actually make cities primary sources of risk factors leading to modern diseases. The authors conclude that with increasingly large proportions of people living in cities effective ways to handle the urban environmental risk transition must be identified. Rapid economic growth in the city of Visakhapatnam, which is now one of India's largest ports and an important industrial town beside seaside resort/retirement centre. It highlights how the city's further growth is constrained by inadequate investment in infrastructure - especially for water and electricity - and discusses the political and institutional reasons for this. It then presents the findings of participatory research on poverty, and the many dimensions of poverty, which are emphasized by urban poor groups, including inadequate incomes, lack of assets ("no shelter, no property, no gold"), lack of support (especially for widows, deserted women and the handicapped), illness and debt. It discusses the direct and indirect impacts on poverty of a DFID slum improvement project.

\section{Socio-economic conditions of the selective study area}

Socio-economic variables viz age, sex, martial statues, nature of the family, family size, education, migration, religion, social background etc are examined in order to draw the socio-economic profile of the sample households.

6.1 It is found that a majority of heads of the sample households belong to effective age group i.e., 31-45. With regard to educational status, more than 50 percent of the heads of the households possessing education belong to SC category followed by BC, OC and ST castes. It is equally interesting to note from the analysis that more than 49 percent are illiterates under the category of SC followed by $\mathrm{BC}$ and a similar picture is observed in the 
Hazardous slum-1 but in the hazardous slum-2 the illiterate percentage is more when compared to Hazardous slum-1.

6.2 It can be found from the migration more than 50 percent of the sample households are migrants from rural to urban. A majority of the sample households are migrating from rural to urban in the Hazardous slum- 1 slum when compared to hazardous slum-2. But in the Hazardous slum-2, most of the migrants are from within the city.

6.3 From the Religion side majority of the Christians are in the Hazardous slum-1 slum, majority of the Hindus are in the Hazardous slum-2. With regard to social background and occupational structure in the study area is SC's are predominant in the hazardous slum-1 and BC's are predominant in the Hazardous slum-2. The occupational structure in the laborers the slums is almost the same, while majority of the sample households are casual labourers in the Hazardousslum-1

\section{Statistical Excercises:}

An economic analysis for Decision to dwell in this slums factors influencing:

In this section, the focus is to estimate the probability that the household in decision to dwell in hazardous slums is based on maximum livelihood estimates obtained from the associated probability Model. Also, to assess the magnitude of impact of an explanatory variable, it can be also computed that corresponding 'marginal effect' by using STATA package. This analysis has been carried out for the entire selected sample of 500 in the study area

\section{1 probit Model :}

The probit model states with the notation that the underlying the household decision to dwell in Hazardous slum-1 is a latent variable (say, $\mathrm{Y}^{*}$ ), which is determined by a set of socio-economic factors, that is $\mathrm{x}_{\mathrm{j}}$, hence, the latent equation is:

$$
Y^{*}=x_{j} \beta_{j}+u_{i j}
$$

It can be written as simple form,

$\mathrm{Y}=\alpha+\beta_{1} X_{1}+\beta_{2} X_{2}+\beta_{3} X_{3}+\beta_{4} X_{4}+$ ui

Where $\mathrm{Y}=$ The household decision to dwell in the Hazardous slum-1 it can be given a value of 1 , otherwise- 0

$\mathrm{X}_{1}=$ If the Head of the Household is an illiterate-1, otherwise-0

$\mathrm{X}_{2}=$ Family Size in number

$\mathrm{X}_{3}=$ If the household having poor income-1, otherwise-0

$\mathrm{X}_{4}=$ If the household migrant from rural to urban-1, otherwise-0

and $\mathrm{u}_{\mathrm{i}}$ is the error term

\subsection{Results and discussions:}

7.2.1 For the total Model, independent variables are selected in 4 in number to carry out the analysis. Among the 4 independent variables four variables Literacy status $\left(\mathrm{X}_{1}\right)$, family size $\left(\mathrm{X}_{2}\right)$, Poor Economic Status $\left(\mathrm{X}_{3}\right)$ and Migrant from Rural $\left(\mathrm{X}_{4}\right)$ are turned out to be statically significant at different significance levels.

7.2.2 The result of the Probit indicates that the variable literacy staus $\left(X_{1}\right)$ is statistically significant at 10 percent level of chi-square value with expected positive sign. The probability of the Head of the household is illiterate then the household decision to dwell in Hazardous slum-1 is significantly increases by 26.4 percent, looking at marginal effect of this variable indicates that the magnitude of impact is very significant ( 3.8 percent) in the Hazardous slum-2 slum when compared to Hazardous slum-1.

7.2.3. 7The variable family size $\left(\mathrm{X}_{2}\right)$ is also statistically significant at 1 percent level of chi-square value with expected positive sign. The probability of the family size is higher likelihood of the household decision to dwell in Hazardous slum-1. is higher likelihood i.e. a one percent change in family size leads to 17.5 percent of probability of chance of the household's decision to dwell in Hazardous slum-1. The Marginal effect of this variable clearly shows that the magnitude of impact is very large i.e. 47.6 percent in Hazardous slum-1 when compared to Hazardous slum-2.

.2.4. The variable poor income status $\left(\mathrm{X}_{3}\right)$ is turned out to be statistically significant at 10 percent level of chisquare value with expected positive sign. When the household income is poor then the probability of the household decision to dwell in Hazardous slum-1 significantly increases by 43.1 percent, and looking at marginal effect of this variable indicates that the magnitude of impact is significant (10.1 percent) in the Hazardous slum-1 when compared to Hazardous slum-2.

7.2.5. Finally the variable Migrant from Rural $\left(X_{4}\right)$ is also statistically significant at 1 percent level of chi-square value with expected positive sign. For the household is migrating from rural area, the household decision to dwell in Hazardous slum-1 significantly increases by 155.2 percent, looking at marginal effect of this variable 
indicates that the magnitude of impact is significantly very high (55.4 percent) in the Hazardous slum-1 when compared to Hazardous slum-2.

7.2.6. When the household income is poor then the probability of the household decision to dwell in Hazardous Slum-2 significantly increases by 43.1 percent, and looking at marginal effect of this variable indicates that the magnitude of impact is significant (10.1 percent) in the Hazardous Slum-1 when compared to Hazardous Slum2.

7.2.7. The probability of the Head of the household is illiterate then the household decision to dwell in

Hazardous Slum-1 is significantly increases by 26.4 percent, looking at marginal effect of this variable indicates that the magnitude of impact is very significant (3.8 percent) in the Hazardous Slum-1 when compared to Hazardous Slum-2.

7.2.8. For the household is migrating from rural area, the household decision to dwell in Hazardous Slum-1 significantly increases by 155.2 percent, looking at marginal effect of this variable indicates that the magnitude of impact is significantly very high (55.4 percent) in the Hazardous Slum-1 when compared to Hazardous Slum-2.

\begin{tabular}{|c|c|c|c|c|c|}
\hline \multicolumn{6}{|c|}{$\begin{array}{l}\text { Table-2 Probity analysis for factors affecting the household decision } \\
\text { to dwell in the Hazardous slum-1 Vs Hazardous slum-2 }\end{array}$} \\
\hline \multicolumn{4}{|c|}{ 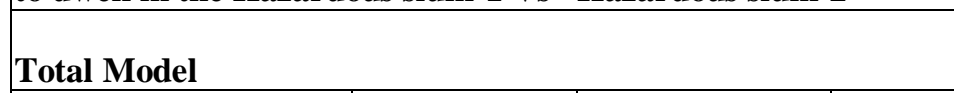 } & \multicolumn{2}{|c|}{ Marginal effects $\left(\frac{d y}{d x}\right) *$} \\
\hline Independent Variable & Coefficient & Standard error & p-value & Hazardous Slum-1 & $\begin{array}{l}\text { Hazardous Slum- } \\
2\end{array}$ \\
\hline Literacy status (X1) & $0.2642443 * * *$ & 0.1528585 & 0.084 & -0.1052795 & 0.0668269 \\
\hline Family size (X2) & $0.1754092 *$ & 0.0580542 & 0.000 & -0.5454813 & 0.0698861 \\
\hline $\begin{array}{l}\text { Poor income status } \\
\text { (X3) }\end{array}$ & $0.4314778 * * *$ & 0.3161396 & 0.132 & -0.170738 & 0.0698862 \\
\hline $\begin{array}{l}\text { Migrant from rural } \\
\text { (X4) }\end{array}$ & $1.551767 *$ & 0.3219791 & 0.000 & 0.5578434 & 0.0032120 \\
\hline \multicolumn{6}{|c|}{$\begin{array}{l}\text { No. of Observations }=500 \\
\text { Constant }=5.274618 \\
\text {-Log likelihood }=-195.56626 \\
\text { Pseudo } R^{2}=0.3877 \\
\text { Prob }>\chi^{2}=0.0000\end{array}$} \\
\hline
\end{tabular}

Note-1: * indicates the variable significant at 1 percent level.

** indicates the variable significant at 5 percent level

*** indicates the variable significant at 10 percent lev

Note -2: Predicted probability of decision to dwell in hazardous slum-2 is 0.5204675

\section{Logistic Regression Model:}

We used logistic Regression Model for hazardous slum through environment like four independent variable ie., sound pollution, dust pollution, smoke pollution and water pollution

$\operatorname{Ln}\left(\frac{p}{1-P}\right)=\alpha+\beta_{1} X_{1}+\beta_{2} X_{2}+\beta_{3} X_{3}+\beta_{4} X_{4}+$ ui

Where $\alpha-$ is the constant term

$\beta_{1}$ to $\beta_{2}$ are the coefficients of the respective independent variables

$X_{1}$ - Dummy variable that takes the value of 1 if the household opines that sound pollution is the cauase for chronic disease.

$X_{2}$ - Dummy variable that takes the value of 1 if the household opines that dust accumulation is the cauase for chronic disease.

$X_{3}$ - Dummy variable that takes the value of 1 if the household opines that smoke pollution is the cauase for chronic disease.

$X_{4}$ - Dummy variable that takes the value of 1 if the household opines that water pollution is the cause for chronic disease.

and ui is the error term. 
Using STATA- Statistical package results have been estimated for both models. The step-wise logistic regression method uses to chi-square test to identify which variable add or drop automatically. The results are interpreted with the help of odds ratio i.e. $\mathrm{e}^{\beta \mathrm{i}}$, instead of the actual coefficient, as the interpretation of odds ratio is more intuitive. It would mean that for a unit change in the independent variable there would be a corresponding change in the Odds Ratio.

\section{Conclusions}

This study brought out some interesting conclusions, which are very useful in formulating policies for environmental and health aspects of the living conditions of the slum dwellers in general and Visakhapatnam in particular. Some of the important conclusions of the study are as follows:

9.1. The results of the logistic regression model indicate that the variable sound pollution $\left(\mathrm{X}_{1}\right)$ is statically significant at 5 percent level of $\chi^{2}$ - value with expected positive sign. The odds ratio associated with this variable 1.37 times more likely to impact than with their counterpart's i.e. the household's one who had not suffering chronic diseases and vice -versa.

9.2. The variable Dust accumulation $\left(\mathrm{X}_{2}\right)$ is statistically significant at 1 percent level of $\chi^{2}$ - value with expected positive sign. The odds ratio of this variable indicates that 2.61 times more likely to the impact on those who are suffering chronic disease than their counterparts.

9.3. The variable Water pollution $\left(\mathrm{X}_{4}\right)$ is statistically significant at 10 percent level of $\chi^{2}$ - value with expected positive sign. The odds ratio shows that the sound pollution has 2.3 times more likely to impact on those who are suffering from chronic disease than their counterparts in the study area.

9.4. In the Hazardous slum-1, there were 250 observations and independent variable 3 in number to carry out the binary logit analysis. Thus, there were three independent variables to begin with. From these, Smoke pollution $\left(\mathrm{X}_{3}\right)$ and Water pollution $\left(\mathrm{X}_{4}\right)$ are turned out to be statistically significant at 1 percent and 10 percent levels of $\chi^{2}$ - value with expected positive signs. The odds ratio associated with these variables has 1.95 and 1.58 times higher the impact for those who are suffering from chronic disease compared to their counterparts and vice-versa.

9.5. For Hazardous slum-2, there were 250 observations and independent variable 3 in number to carry out the binary logit analysis. Thus, there were three independent variables to begin with. From these, Sound pollution $\left(\mathrm{X}_{1}\right)$ and Dust accumulation $\left(\mathrm{X}_{2}\right)$ are turned out to be statistically significant at 5 percent levels of $\chi^{2}$ value with expected positive signs. The odds ratio associated with these variables has 1.03 and 1.62 times higher the impact for those who are suffering from chronic disease compared to their counterparts and viceversa.

\section{Suggestions:}

According to this study both slums are suffering with environmental factors different aspects these two slums are hazardous slums because they must change to rehabilitate another area within the city for their live stocks.

10.1 In view of the large scale migration from the rural to urban centers necessary steps are to be taken to meet the sanitary and hygiene problems. The Community Health Department of GVMC should prepare short run and long run programmes to meet the sanitary problems of the flooding population.

10.2. Various Schemes for Slum Improvement programmes implemented by Central, State Government and ODA projects also But strictly allocate to the grants for Slum improvement and slum Environmental improvement Schemes like Housing, drinking water, drainage \&sewerage facilities, public health Dispensaries, and urban Infrastructure facilities.

10.3 The residents of the slums in and around that area leakage victim of pollution vigorous steps to control dust and sound pollutants.

10.4. The residents of hazardous slum-1 (priyadarsini colony) lack of basic civic amenities as they are residing in a disputed area. The residents are exposed to hazardous pollutants that are causing all types of diseases. To safeguard them, the better option would be to relocate them to some other area which is slum free area.

10.5 The general awareness on environment and public health issues are to be brought in the slums by government and NGO's through street plays like drama, documentary movies and etc. That will have immense impact on the attitude towards living styles of the slum dwellers. 


\section{References:}

[1] B.Survyaswara rao ,G.Ramachandrudu,and T.Venkatraju (1993),“ evolutionary study of the Visakhapatnam slum improvement project. by ODA, IDPS.

[2] United Nations Human Settlements Program (2003), “ The Challenge of Slums: Global Report on Human Settlements”, 2003. Nairobi: UN-HABITANTS

[3] K.Vidyavathi, Explained the growth of slums in india-an economic analysis of 2001,censis figure.

[4] M.Shivasankaraiah, K. Thulasi Naik and K.Dasaratharamaiah(2008), discussed about Environmental pollution, SOUTHRN ECONOMIST June 1, 2008.,

[5] C R Sridhar(2006) Sky Above, Mud Below , slum Demolition and Urban Cleansing, Economic and political weekly, June24,2006 Vol:XLI, No.25, pp2529-2631.

[6] Dr. Devaram A.Nagdeva (2002),IUSSP Regional Population Conference on Southeast Asia's population in changing Asian context at Bangkok, Thailand, 10-13 June 2002.

[7] David Vlahov, Nicholas Freudenberg and et al. (2007), "Urban as a Determinant of Health", Journal of Urban Health, Vol. 84, No. 1, p.p: 16-26.

[8] Elizabeth Wambui Kimani-Murage and Augustine M. Ngindu (2007), "Quality of Water - the Slum Dwellers Use: The Case of a Kenyan Slum", Journal of Urban Health, Bulletin of the New York Academy of Medicine, Vol. 84, No. 6, p.p: 829-839.

[9] Smith K.R. and Lee Y.S. (1993), "Urbanization and environmental risk transition", Sage publications, California, p.p: $108-120$.

[10] Philip Amis and Sashi Kumar (2000), 'Urban economic growth, infrastructure and poverty in India: lessons from Vishakapatnam', Journal of Environment \& Urbanization, Vol.12 No 1 April 2000, p.p: 185-196. 